\title{
Experiences from developing a new course in mechatronics
}

\author{
Hansen, Søren; Ravn, Ole
}

Published in:

Proceedings of 16th International Conference on research and Education in Mechatronics

Link to article, DOI:

10.1109/REM.2015.7380383

Publication date:

2015

Document Version

Peer reviewed version

Link back to DTU Orbit

Citation (APA):

Hansen, S., \& Ravn, O. (2015). Experiences from developing a new course in mechatronics. In Proceedings of 16th International Conference on research and Education in Mechatronics (pp. 135-138). IEEE.

https://doi.org/10.1109/REM.2015.7380383

\section{General rights}

Copyright and moral rights for the publications made accessible in the public portal are retained by the authors and/or other copyright owners and it is a condition of accessing publications that users recognise and abide by the legal requirements associated with these rights.

- Users may download and print one copy of any publication from the public portal for the purpose of private study or research.

- You may not further distribute the material or use it for any profit-making activity or commercial gain

- You may freely distribute the URL identifying the publication in the public portal

If you believe that this document breaches copyright please contact us providing details, and we will remove access to the work immediately and investigate your claim. 


\title{
Experiences From Developing a New Course in Mechatronics
}

\author{
Søren Hansen and Ole Ravn \\ DTU Electrical Engineering, Tech. Univ. of Denmark, Elektrovej B. 326, Lyngby, DK-2800 \\ (E-mail: $\{s h, o r\}$ @elektro.dtu.dk)
}

\begin{abstract}
Experiences from a new course in mechatronics at Technical University of Denmark are conveyed in this paper. The course is supposed to teach students enrolled in the bachelor degree in electrical engineering some fundamental knowledge about mechanics and to teach students enrolled in the bachelor degree in mechanical engineering fundamentals about electronics. Furthermore the course uses project work as a method to keep the students actively participating and in part have them teach each other the subjects. The general course plan is presented and the reasoning behind the course structure is discussed in the paper, together with a brief look at the student's reactions in form of data from the course evaluation.
\end{abstract}

\section{INTRODUCTION}

This paper describes the development and experiences from running a new course teaching mechatronics, automation and robotics at Technical University of Denmark (DTU). At DTU the main group researching in robotics is placed within the Department of Electrical Engineering. For this reason many of the research topics in focus are on the electronic side of robotics, which are sensors, controllers and signal processing. Less focus is put on the mechanical design consideration. This uneven focus also reflects the educational side of robotics where there is a strong program at electrical engineering (see [1]). However this program mostly attracts students studying the electrical engineering degrees and not so many from mechanical engineering and computer science. As robotics is highly cross-disciplinary it would be advantageous to have students enrolling with a mixed range of skills and background knowledge. This would be beneficial for their education but also strengthen robotics research in the long run.

One solution to this issue is to create a dedicated study program which teaches subjects from several of the classical engineering disciplines, for example a mechatronics line or mechatronics course program. Many leading technical universities have exploited this opportunity and offers programs or courses with this subject, fx. MIT [2] and Georgia Tech [3], to mention a few. The main dilemma in these programs is to find a suitable balance between the core knowledge of each field and the variety of subjects [4].

Another solution, which does not entail large changes to the existing educational program structure, is to create a joint course which includes topics of both disciplines, but tailors the teaching to the specific students needs. Ideally every student would receive an individual amount of knowledge to fit his or her needs, however this is obviously not practically possible.
The practical solution implemented in DTU's new course "31373: Automation, Components and Systems"1 is to divide the students into an electronics team and a mechanics team. The electronics team is made up of students enrolled on the electronics engineering program and similar for the mechanics team. The electronics team receives teaching in the basic knowledge of mechanics and vice versa.

To avoid just running two parallel courses, a project element is added to the curriculum. This basically consists of designing and building a prototype of an electro-mechanical system of student choice. During the project part the students are mixed into groups of approximately four people. Each group consists of participants from both the electronics team and the mechanics team such that the group contains knowledge from both disciplines. It is now the intention that in solving the practical project the students teach each other about their field of expertise. It is also the hope that in working with a practical problem the students are more motivated towards learning the theories needed to solve the task. It is well known that to create motivated students they need to be actively engaged in solving a task related to the curriculum [5].

The course has now run two times in spring 2014 and spring 2015 which has given some practical experiences and considerations we wish to convey in this paper. The paper is structured in the following manner. In Section II a general description of the course is given. This has emphasis on how the projects are designed and carried out. Section III shows results from student evaluation of the course and finally a summary is given.

\section{COURSE DESCRIPTION}

This section will describe the different elements of course 31373 in details, as well as provide reflections and design consideration about the course structure.

From the beginning it was a key point to create a course with a high degree of student involvement. This is evident in that more than $50 \%$ of the available course time is managed by the students.

\section{A. Course Plan Layout}

Technical University of Denmark uses a semester structure consisting of two longer terms of 13 weeks of teaching combined with a number of 3 week periods for more intense and

\footnotetext{
${ }^{1}$ The course description is found at: http://www.kurser.dtu.dk/20152016/31373.aspx?menulanguage $=\mathrm{en}-\mathrm{GB}$
} 
practical courses. Course 31373 is placed in the spring term each year which gives 13 teaching modules corresponding to 5 ECTS $^{2}$ credits.

The timetable of the program is shown in Table I. The general idea behind this plan is to use an equal amount of the time on regular teaching and project work. In the weeks 2-3 and 5-7 regular teaching with a fixed curriculum is carried out. This is mixed with project work, where the teachers' acts as consultants but no scheduled teaching is carried out. The last day every group presents their project and evaluates another group's solution.

\section{B. Subjects and learning objectives}

The fixed schedule in weeks 2-3 and 5-7 contains the following topics and learning objectives.

The electronics team starts out with an introduction to mechanical design and does exercises in drawing objects in the 3D CAD system SolidWorks. The on-going exercise is to draw a model of the Lego human ${ }^{3}$. During the 5 weeks of teaching they go through an introduction to forces and statics, tension in materials as well as learning to create $3 \mathrm{D}$ printed objects. The modules end up with a practical exercise using DTU's collection of Ultimaker 3D printers to print an object.

The learning objectives for the electronics team are the following

- Explain the principles and methods in design for construction.

- Make 3D CAD drawings of mechanical parts.

- Use a 3D printer to print mechanical parts for robots and similar objects.

- Explain the meaning of forces and material strength in a simple element, fx. a joist.

The mechanics students get introduced to the basics of ana$\log$ and digital electronics. Hands-on exercises are carried out using breadboards and the Arduino platform. These exercises concerns topics of measurement of digital and analog signals, serial communication and motor-control. Using the Arduino platform it is possible for the students to create fairly advanced solutions, even though they start out with almost no knowledge about electronics.

For the mechanics team the learning objectives are as follows

- Explain how analog circuits with resistors, capacitors, inductors, diodes, transistors and opamps work.

- Use multimeters and oscilloscopes to troubleshoot electrical circuits.

- Explain the principles and challenges in using digital controllers for measuring of signals and control of different actuators.

- Program and troubleshoot programs for microcontrollers, fx. with the Arduino platform.

\footnotetext{
${ }^{2}$ European Credit Transfer System, http://www.studyineurope.eu/ectssystem

${ }^{3}$ http://www.lego.com
}

The following learning objectives are setup for the project period. The main emphasis here is that the students should be able to tackle an electro-mechanical problem in an analytic way.

- Analyse and solve an automation task unassisted and across study fields.

- Troubleshoot electro-mechanical systems.

Another important aspect is independent problem solving. As the course usually has many participants the teachers' time for each group is somewhat limited. This usually induces groups to help each other out.

\section{Project Work}

One of the best ways to get students motivated for learning is to trigger their intrinsic interest in the subject [5]. Therefore it is a desire to keep the students as much involved in the design of the project work as possible. This involvement is achieved in three steps.

1) Creation of project proposals.

2) Design of project formulation and scope.

3) Actual project work.

The process starts on the first day of the course, where the students are given the task of proposing projects that they would like to work with during the course. The only limitations they are given are that the proposed projects should include both a mechanical and an electronic element and it should be realistic to complete in the available time.

The project proposals are then reviewed by the course teachers. The review process ensures the removal of proposals that are unrealistic to implement either for time-wise or economic reasons. The remaining proposals are then advertised and students are told to sign up for three projects in a prioritised order. When all participants have signed up, the projects with fewer than two people are removed and the remaining projects are those that are actually carried out. The considerations of project group formation are described in section II-E.

This proposal process can be quite difficult to control because many students have an unrealistic idea of how much time it takes to implement electro-mechanical systems. Therefore it is extremely important to filter out projects that are too difficult. If students are given an unrealistic task, they are fairly quickly demotivated and the opposite effect of what is intended occurs.

The student proposals usually include building small mobile robots, robotic arms and similar gadgets. But the proposals also include very specific machines as fx. a foam cutter or a 3D print cleaning system. An example of a successful project is the small robotic arm shown in Fig. 1. This was carried out during the 2015 run of course 31373. The robot was created from laser-cut wooden sheets and actuated by standard hobby servo motors. A simple inverse-kinematic solution made it possible to guide the robots tool to different coordinates specified by the user. The robot was controlled by an Arduino Uno. 
TABLE I: Plan of the course activities.

\begin{tabular}{cl}
\hline Week & Activity \\
\hline 1 & Course introduction and creation of project proposals \\
$2-3$ & Separate teaching in Electronics and Mechanics combined with hands on exercises \\
4 & Group formation and project formulation \\
$5-7$ & Separate teaching in Electronics and Mechanics combined with hands on exercises \\
$8-12$ & Project work \\
13 & Demonstration and evaluation of projects \\
\hline
\end{tabular}

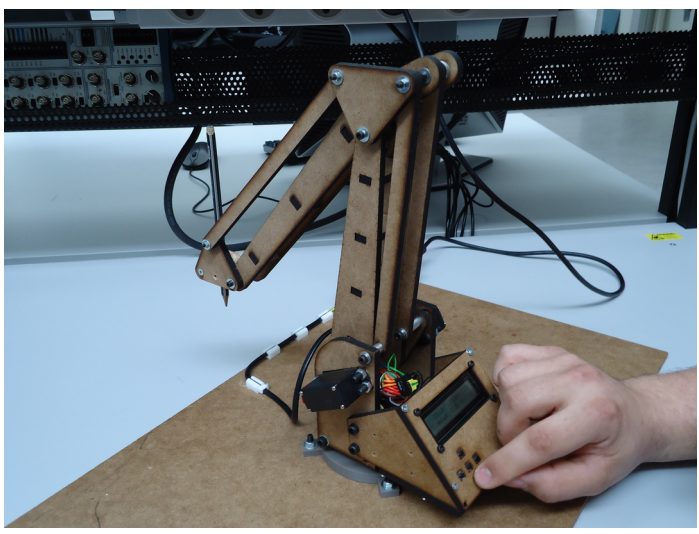

Fig. 1: Model of a robotic arm designed by a group of students.

\section{Student Assessment}

When the course ends, each group hands in a written report describing the design considerations of their project. The reports should contain specification of requirements as well as a technical description of the products mode of operation. A test section that evaluates the products performance with respect to the requirements is also part of the report.

These reports forms the basis of assessing and marking the students. The assessment is done based on how well the report reflects the learning objectives described in Subsection II-B. The marking is done both by the course teachers and an external examiner to ensure a fair and unbiased assessment.

One issue with this way of assessing is that all weight is put on the work done in the final project. This means that the work done in the hands-on exercises during the fixed scheduled parts of the course is not marked. This can compel some students to not put that much effort into these parts of course. To counteract this tendency it has been considered to also assess the hands-on exercises and let this count as a certain percentage of the final mark, in future versions of the course.

The average of the marks given in both 2014 and 2015 was 10.1 according to the Danish 7 -step-scale ${ }^{4}$. The mark 10 corresponds to $B$ on the ECTS marking scale. This is a high average mark and reflect that very good projects were made both in 2014 and 2015. It seems to indicate that the students are willing to put up an extra effort when working with a project of their own desire. There is no indication that students from one study program scores better marks than others.

\footnotetext{
${ }^{4}$ http://en.wikipedia.org/wiki/Academic_grading_in_Denmark
}

\section{E. Formation of Project Groups}

The basis for forming the project groups are described in this section. The following considerations guides the group formation

- Projects should fit the student's wishes, to achieve intrinsic motivation.

- Students with both electronic and mechanical backgrounds should be in each group, such that a mixture of knowledge is present.

- The group formation should accommodate other wishes if it does not go against the two points above.

The group formation is done based on the projects that the students sign up for and groups should have at least three, but preferably four members. In a few cases groups of 5 students has been allowed, but larger groups are generally not established since it is hard to ensure an even work load distribution among the group members.

In practice it turns out to be difficult to fully satisfy the above points and therefore mainly the objective of intrinsic motivation is accommodated. The main issue is that there is no control of who enroll in the course. In Fig. 2 and 3 the distribution of the students backgrounds for the two years are shown.

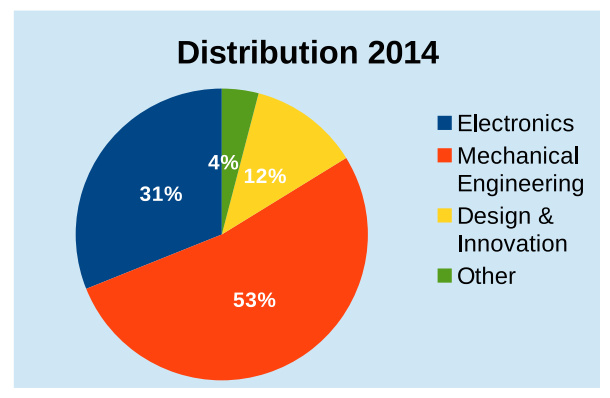

Fig. 2: Distribution of course participants based on their subject (2014).

In 2014 (Fig. 2) 31\% came where from the bachelor in electronic engineering and $65 \% 5$ had a mechanical background. In 2015 (Fig. 3) the numbers where reversed as 63\% where from electronics and $36 \%$ from mechanics. This meant that a few groups with only one expertise where allowed, both years. In practice this has not been visible on these groups' results. The main reason for this is that the students during the course gets

\footnotetext{
${ }^{5}$ Both participants from "Mechanical Engineering" and "Design \& Innovation" are considered to have mechanical backgrounds in this context.
} 


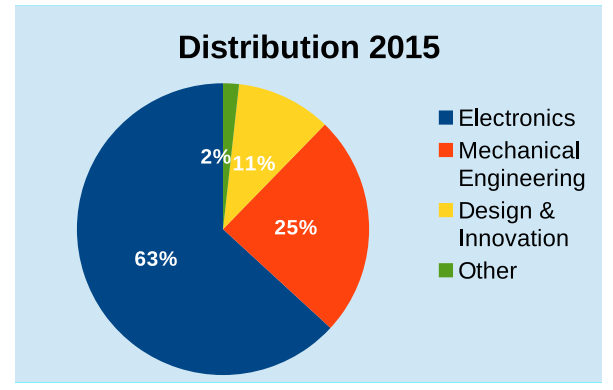

Fig. 3: Distribution of course participants based on their subject (2015).

to know who has what skills, and get help from these people even though they are not in the same group.

\section{EVALUATION}

All DTU courses are evaluated by the participants in several ways. The main evaluation is done during the final weeks of the semester and consists of a questionnaire of statements that each student should fill out electronically. Each statement has 5 answers from "strongly agree" to "strongly disagree". In this section a brief discussion of the two most important questions, in this context, are shown. One thing to keep in mind with this evaluation is that it has a low response rate of around $50 \%$.

In Fig.4 results of the statement "I think I learn a lot in the course" are shown. This shown the about that only about

\section{I learn a lot}

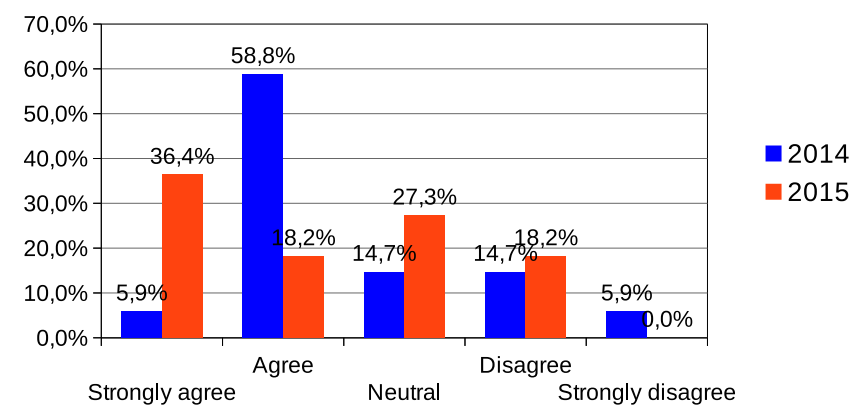

Fig. 4: Student evaluation of the learning outcome of the course.

$55 \%-60 \%$ of the students are agreeing with this statement which is lower than expected. One reason for this could be that some students tend not to take responsibility when doing group work. Some groups tend to have one or two leaders that are very active and a few "followers" who sometimes feel a bit left out and therefore feel they get less out of the course.

In Fig. 5 the results of the statement "I think the teaching method encourages my active participation" are shown. This shown that $75 \%-80 \%$ of the students agree with this. This is definitely in line with the expectations and hopefully also gives rise to intrinsic motivation amongst the students.
Teaching encourages my active participation

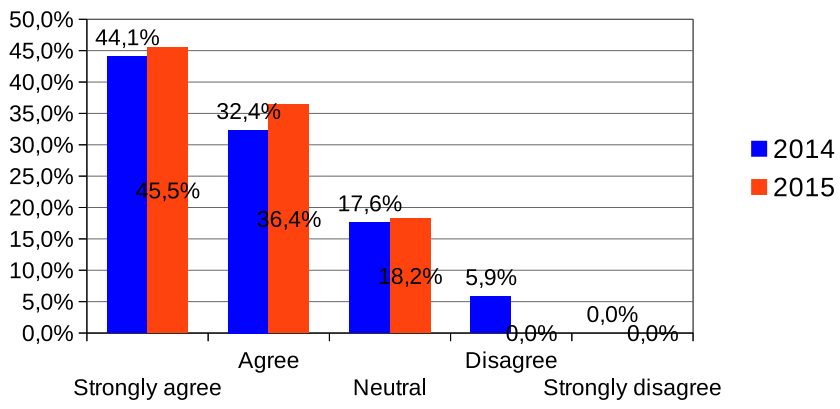

Fig. 5: Student evaluation of how active they are.

\section{SUMmary}

The structure and content of a new course with participants from two different study programs were presented. The course was designed to teach mechatronic topics in a different way. Students were divided into groups based upon their line of study and taught separately. Then they were mixed together in groups and given a practical task to solve. This created a high degree of motivation and activity by the students. The learning outcome was according to the evaluation a bit lower than expected, but still reasonably satisfactory.

\section{REFERENCES}

[1] O. Ravn and N. A. Andersen, A Course Programme in Mobile Robotics with Integrated Hands-on Exercises and Competitions. Springer, 2010, ch. Trends in Intelligent Robotics, pp. 266-273.

[2] D. L. Trumper and S. J. Ludwick, "Development of 2.737 mechatronics at mit," in Proceedings of the 1999 IEEE/ASME International Conference on Advanced Intelligent Mechatronics, 1999.

[3] C. F. Bergh, A. Kita, and I. C. Ume, "Development of mechatronics course in the school of mechanical engineering at georgia tech," in Proceedings of the 1999 IEEE/ASME International Conference on Advanced Intelligent Mechatronics, 1999.

[4] V. V. Vantsevich, Mechatronics in Action. Springer, 2010, ch. 12 (Education in Mechatronics), pp. 197-218.

[5] J. Biggs and C. Tang, Teaching for Quality Learning at University, 4th ed. McGraw-Hill, 2011. 